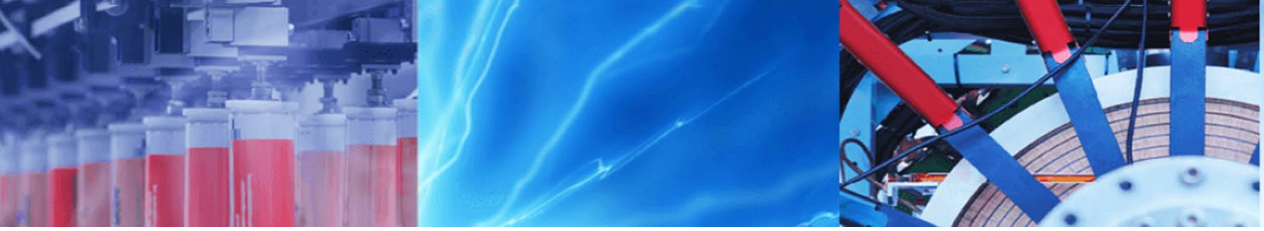

Research Article

\title{
The relationship between resistances measured by two-probe, Wenner probe and C1760-12 ASTM methods in electrically conductive concretes
}

\author{
Heydar Dehghanpour ${ }^{1} \cdot$ Kemalettin Yilmaz $^{1}$
}

Received: 28 August 2019 / Accepted: 28 November 2019 / Published online: 2 December 2019

(c) Springer Nature Switzerland AG 2019

\begin{abstract}
In recent years, the investigation of electrically conductive concrete between construction building materials has been one of the interesting subjects. Therefore, it is important to examine and compare electrical resistance measurement methods. In previous studies, the resistance of electrically conductive concretes was measured by different methods. In this study, it is aimed to measure the resistivity value by three different methods and compare them with each other. For this purpose, two-phase electrical conductive concretes with eight different mixes and additional control concrete were produced. Two different proportions of carbon fiber and four different ratios of recycled nanocarbon black were used in the mixtures. The electrical resistivity of the produced cylindrical specimens was measured by two-probe, Wenner probe and C1760-12 ASTM methods. According to the regression coefficients obtained in the results, the linear relationships between the resistivity values measured with all three methods were found to be appropriate. In addition, the nanocarbon black additive used significantly increased the conductivity of carbon fiber. Nanocarbon black and carbon fiber have also been useful in improving the compressive strength of electrically conductive concretes.
\end{abstract}

Keywords Electrical conductive concretes · Nanocarbon black · Carbon fiber · Two-probe · Wenner probe · C1760-12 method

\section{Introduction}

The electrical resistance of the concrete is defined as the resistance against the current when a voltage is applied to a concrete mass. Also, the resistivity is the resistance obtained at the unit area/length. Previously, the electrical resistance of the concrete was measured for durability and corrosion detection [1]. In recent years, researches have been continuing on electrical conductive concretes (ECCs) with different usage areas. What is important about ECCs is research topics, materials used, mixture optimization, specimen geometry effects and different methods of measurement [2-6]. ECCs can be applied for the crack detection and strain sensing in construction elements [7] and can be used as an electromagnetic radiation reflector to protect the electromagnetic interference [8-10]. Also, ECCs can be used as self-heating plate for prevent snow and ice in road pavements [11-14].

The conductivity or electrical resistance of ECCs is generally measured in bulk (uniaxial) or superficial manner [15]. Bulk resistance (BR) is measured by the two-point method, and the surface resistance (SR) is obtained by the four-point or the Wenner probe method $[15,16]$. In the two-point method, a voltage difference is applied between the two ends of the concrete specimen, the current realized as a result of the applied voltage is measured and the resistance is obtained by the Ohm law $[8,17,18]$. In the four-point method, a four-probe device is placed

Heydar Dehghanpour, heydar.dehghanpour@ogr.sakarya.edu.tr | ${ }^{1}$ Civil Engineering Department, Engineering Faculty, Sakarya University, 54187 Sakarya, Turkey. 
on the surface of the concrete specimen, a voltage difference is applied between the two medium probes and the amount of current between the two external probes is measured and the resistance $(R)$ is obtained by using the Ohm law. The resistivity of the specimen is obtained by multiplication of coefficient $2 \pi a[15,16,19]$. Here, $a$ is the distance between the probes.

Sassani et al. [8] measured the resistances of ECCs produced for the purpose of optimizing in different mixtures by two-point uniaxial method. They were produced the specimens in the form of a $10-\mathrm{cm}$ cube and, as electrodes, buried a metal mesh parallel to the two surfaces of the specimen. The resistance was calculated based on the amount of current that occurred as a result of the applied voltage between the two meshes. The resistance values found in the study of Sassani were in agreement with the resistance values of concretes containing carbon fiber in the literature [20]. Similarly, Wu et al. [21] and El-Dieb et al. [17] measured the resistance of conductive concrete specimens they produced using two-point uniaxial method. However, it has been found that the normal concrete has bulk resistivity between $6.54 \times 10^{5}$ and $11.4 \times 10^{5} \Omega \mathrm{cm}[8$, $22]$, and the resistivity of conductive concretes with different mixtures is between $30 \Omega \mathrm{cm}$ and $1 \times 10^{4} \Omega \mathrm{cm}[8$, $17,20,21]$.

Frank Wenner proposed the four-point resistance measurement method to measure the surface conductivity of concretes in 1915 [23]. This technique is recommended for the measurement of semi-homogeneous materials generally [24]. However, since the concrete is a non-homogenous composite material, the specimen geometry, size and prop spacing are effective on the resistance value measured by this method [5]. several authors were examined the relationship between SR and BR $[4,15,16]$. Ghosh found the SR/BR ratio to be 2.6 on average for different mixtures [4], in another study measured between 2.13 and 3.45 [15]. This also, explains that different mixtures have an effect on the change in the SR/BR ratio. In addition, the ratio of the resistivity of the $100 \times 200$ cylindrical specimen to the resistivity of the $100 \times 300$ cylindrical specimen was found to be 1.56 in Ghosh's study [4]. Noushinin et al. [16] have obtained SR/BR ratio as 2.70 for $100 \times 200$ cylindrical specimens.

Resistance measurement methods mentioned above are commonly used methods in laboratory environment. Generally, the advantage of these methods is that they do not require standard equipment. Even so, it is the C176012 ASTM method, which is the standard for the measurement of electrical bulk conductivity of concrete. However, in order to measure the bulk conductivity of concrete in the C1760-12 ASTM method, a standard device must be used. In this study, it is aimed to measure the resistance of ECCs in different mixtures by three different methods. The relations between the method results will be presented as estimated equations.

\section{Materials and methods}

\subsection{Material properties}

\subsubsection{Cement}

In electrically conductive concretes, high-strength cement is generally used. In this research, 42.5 CEM I R cement was used as binder material. The compressive strength of this cement at 28 days is between 42.5 and $62.5 \mathrm{MPa}$. The physical properties of the cement used are given in Table 1.

\subsubsection{Aggregate}

In previous studies [8], the effect of aggregate grain size and ratio on conductivity in electrical conductive concrete was investigated. Fine aggregates (FA) have a positive effect on the increase in conductivity compared to coarse aggregates (CA). In this study, two different sizes of aggregates were used in equal proportions. The grain size of the FA were $0-5 \mathrm{~mm}$ (Fig. $1 \mathrm{a}$ ) and the CA ones were 5-16 mm (Fig. 1b).

\subsubsection{Carbon fiber (CF)}

Since the purpose of this study is to characterize the conductive concretes with different methods, carbon fiber was used as the most effective conductive additive. CF also has superior mechanical properties (Table 2). Recently, CF has been involved in all areas of the construction industry [25-27]. Two different lengths ( $6 \mathrm{~mm}$ and $12 \mathrm{~mm}$ ) of CF were used in equal ratio. The SEM image of CF is given in Fig. 1c.

\subsubsection{Nanocarbon black (NCB)}

When carbon powder is used in combination with conductive materials in the form of fiber, it provides an advantage in increasing the conductivity [17]. On the

Table 1 Physical properties of 42.5 CEM I R cement

\begin{tabular}{|c|c|c|c|c|c|}
\hline $\begin{array}{l}\text { Initial set- } \\
\text { ting (min) }\end{array}$ & $\begin{array}{l}\text { End set- } \\
\text { ting (min) }\end{array}$ & $\begin{array}{l}\text { Specific } \\
\text { weight } \\
\left(\mathrm{g} / \mathrm{cm}^{3}\right)\end{array}$ & $\begin{array}{l}\text { Volume } \\
\text { expan- } \\
\text { sion } \\
\left(\mathrm{mm}^{3}\right)\end{array}$ & $\begin{array}{l}\text { Specific } \\
\text { surface } \\
\text { Area } \\
\left(\mathrm{cm}^{2} / \mathrm{g}\right)\end{array}$ & $\begin{array}{l}\text { Liter } \\
\text { weight } \\
\text { (g/L) }\end{array}$ \\
\hline $135-180$ & $190-230$ & $3.16-3.21$ & $0-2$ & $\begin{array}{r}3500- \\
4000\end{array}$ & $980-1030$ \\
\hline
\end{tabular}


Fig. 1 Used materials: a fine aggregate, $\mathbf{b}$ coarse aggregate, c SEM image of CF and $\mathbf{d}$ SEM image of NCB
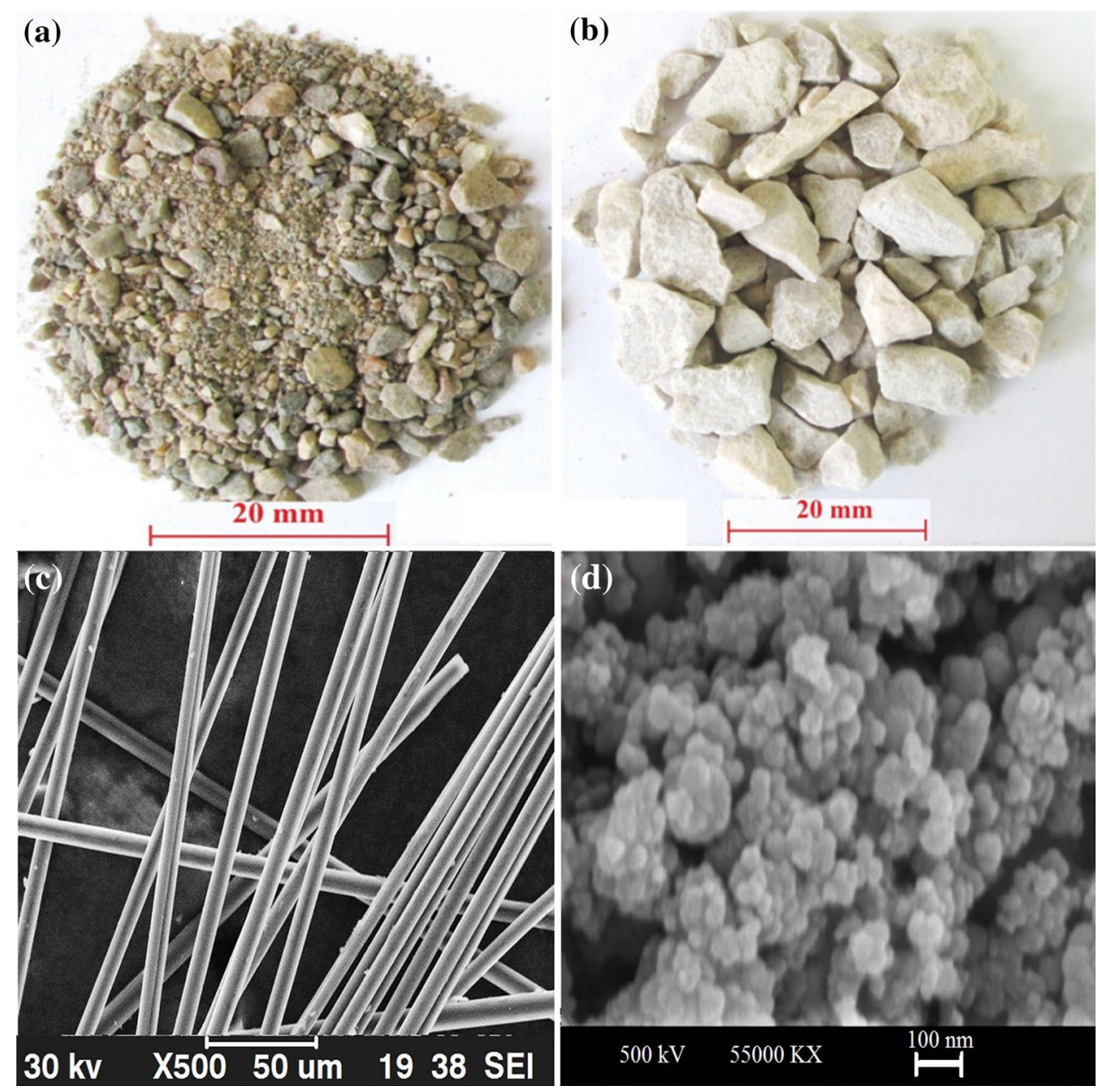

Table 2 Properties of used CF

\begin{tabular}{ll}
\hline Tensile strength & $3800 \mathrm{MPa}$ \\
Modulus of elasticity & $228 \mathrm{GPa}$ \\
Electrical resistance & $0.00155 \Omega \mathrm{cm}$ \\
Specific weight & $1.81 \mathrm{gr} / \mathrm{cc}$ \\
Carbon percentage & $95 \%$ \\
Diameter & $7.2 \mu \mathrm{m}$ \\
\hline
\end{tabular}

other hand, the evaluation of waste materials in concrete is a great advantage in terms of economic and environmental protection [28]. Carbon powder can be obtained from waste tires by burning and pyrolysis methods [29]. Recycled NCB obtained by pyrolysis method was used to increase the electrical conductivity effect in mixtures. NCB obtained by pyrolysis method is located between N200 and N330 according to ASTM nomenclature [30]. The SEM image of the NCB is given in Fig. $1 \mathrm{~d}$.

\subsubsection{Chemical additives}

In order to prevent the need for excess water in the mixtures, the $\mathrm{CHRYSO}{ }^{\circ}$ Delta 2220 commercially called superplasticizer was used. In addition, $0.2 \mathrm{wt} \%$ of the binder, carboxy methyl cellulose (CMC) dispersing material was used for the good dispersion of $\mathrm{CF}$ in the mixture.

\subsection{Mix design}

In previous studies, the CF dosage for ECC was suggested as $0.75-1$ vol\% $[8,11]$. In this study, in two different rate CFs (0.5 and 1 vol\%) and four different rate NCBs were used to produce eight different ECCs. In addition, a control mixture was obtained to determine the compressive strength of the mixture produced. Thus, a total of nine different mixtures, detailed in Table 3, were prepared. In all mixtures CA-FA-cement ratio was taken as 1:1:0.5. The water/cement ratio was fixed to 0.45 . For each of the three different electrical resistance measurement tests and compressive tests, three cylindrical specimens from each mixture were produced. The cylindrical specimens 
Table 3 Materials used in $1 \mathrm{~m}^{3}$ mixture

\begin{tabular}{lllllllll}
\hline No. & Mixture code & FA $(\mathrm{kg})$ & CA $(\mathrm{kg})$ & Cement $(\mathrm{kg})$ & $\mathrm{W}(\mathrm{kg})$ & $\mathrm{NCB}(\mathrm{kg})$ & CF $(\mathrm{kg})$ & SP $(\mathrm{wt} \%)$ \\
\hline 1 & Control & 850.00 & 850.00 & 425.00 & 191.25 & 0.00 & 0.00 & 0.50 \\
2 & N0C0.5 & 846.43 & 846.43 & 423.22 & 190.45 & 0.00 & 9.00 & 1.25 \\
3 & N3C0.5 & 841.33 & 841.33 & 420.67 & 195.04 & 12.75 & 9.00 & 1.25 \\
4 & N6C0.5 & 836.23 & 836.23 & 418.12 & 199.63 & 25.5 & 9.00 & 1.50 \\
5 & N10C0.5 & 829.43 & 829.43 & 414.72 & 205.75 & 42.50 & 9.00 & 1.50 \\
6 & N0C1 & 842.78 & 842.78 & 421.39 & 189.63 & 0.00 & 18.00 & 1.75 \\
7 & N3C1 & 837.68 & 837.68 & 418.84 & 194.22 & 12.75 & 18.00 & 1.75 \\
8 & N6C1 & 832.58 & 832.58 & 416.29 & 198.81 & 25.5 & 18.00 & 1.75 \\
9 & N10C1 & 825.78 & 825.78 & 412.89 & 204.93 & 42.50 & 18.00 & 2.00 \\
\hline
\end{tabular}

$N$ nanocarbon black, $C$ carbon fiber
Table 4 28-day, electrical and compressive test results

\begin{tabular}{llrrrl}
\hline No. & Mixture code & BR $(\Omega \mathrm{cm})$ & $\mathrm{SR}(\Omega \mathrm{cm})$ & ASR $(\Omega \mathrm{cm})$ & $\sigma_{\mathrm{c}}(\mathrm{Mpa})$ \\
\hline 1 & Control & $22,496.10$ & $95,209.00$ & 7291.02 & 44.15 \\
2 & N0C0.5 & 1629.55 & 8799.58 & 3098.68 & 48.15 \\
3 & N3C0.5 & 1438.77 & 4316.31 & 1792.83 & 45.56 \\
4 & N6C0.5 & 222.45 & 560.58 & 708.27 & 45.49 \\
5 & N10C0.5 & 385.78 & 1444.35 & 1087.26 & 42.16 \\
6 & N0C1 & 175.80 & 569.59 & 679.16 & 48.66 \\
7 & N3C1 & 113.03 & 321.46 & 467.73 & 48.86 \\
8 & N6C1 & 80.08 & 188.34 & 450.72 & 47.82 \\
9 & N10C1 & 97.24 & 246.20 & 487.98 & 53.37 \\
\hline
\end{tabular}

$N$ nanocarbon black, $C$ carbon fiber, $S$ steel fiber, $W$ wire erosion

were $20 \mathrm{~cm}$ long and $10 \mathrm{~cm}$ in diameter. All specimens were removed from the molds after $24 \mathrm{~h}$. Specimens were kept in a curing pool filled with drinking water for curing for 7 days. The heads of all prepared cylindrical specimens were cut to $1 \mathrm{~cm}$ thickness for good contact during testing.

\subsection{Test methods}

The aim of this study is to investigate the relationship between three different resistance measurement methods in electrical conductive concrete. These three different methods are two-point uniaxial, four-probe or Wenner probe and C1760-12 ASTM. 10-cm-diameter 20-cm-long cylindrical specimens produced are suitable for all three test methods. The 28-day electrical resistances of the specimens were measured with all three different test methods and then the same specimens were subjected to compressive strength test. The compressive strength test was carried out with a 250-ton universal test device. Electrical and compressive strength results are summarized in Table 4. Three different electrical resistance measurement methods are described below.

\subsubsection{Two-point uniaxial}

The commonly used method for measuring the electrical resistance of concrete is the two-point uniaxial method $[8,17,18,31]$. In this method, the geometry of the specimen whose resistance is to be measured can be in the form of cylinders, cubes prismatic. For the experiment to take place, a voltage difference is applied between the two sides of the specimen (Fig. 2). The resistance value is obtained by putting the amount of current measured by the multimeter into the Ohm's law. Equations 1-3 are used for the calculation of electrical resistivity $[8,17]$.

$V=I R(V)$

$R=\frac{V}{l}(\Omega)$

$\rho=R \frac{A}{L}(\Omega \mathrm{cm})$

Here, $V$ is the applied voltage difference, $I$, the current, $R$, the resistance of the specimen and $\rho$, the resistivity of the specimen.

\subsubsection{Four-probe or Wenner probe method}

The four-probe method is usually used to measure the surface resistances of cylindrical or prismatic specimens $[4,5,15,19]$. In this method, as shown in Fig. 3 , resistance measurement is performed with a four-probe equipment. A voltage difference is applied between the two internal probes, and the electrical current between the two external probes is measured. The electrical resistance is calculated from Eqs. 1-2. Electrical resistivity is obtained from Eq. $4[4,32]$.

$\rho=2 \cdot \pi \cdot a \cdot R$ 
Here $\rho$ is the resistivity of the specimen, $a$, the distance between probes and $R$, the resistance of the specimen.

\subsubsection{C1760-12 ASTM test method}

In this test method, the electrical resistance of a hardened saturated concrete specimen is obtained based on the diffusion of chloride ions [33]. For the realization of the experiment, a 10-cm-diameter, 20-cm-long cylindrical specimen is placed between two cells filled with sodium chloride solution (Fig. 4). A potential difference of 60 volts is applied between two cells. The total current amount within $1 \mathrm{~min}$ between the two cells is measured, and the bulk conductivity of the specimen is calculated from Eq. 5 . (a)

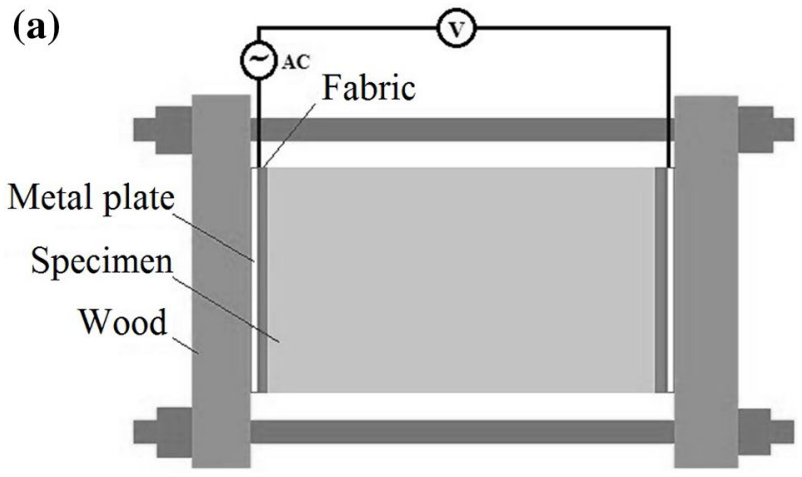

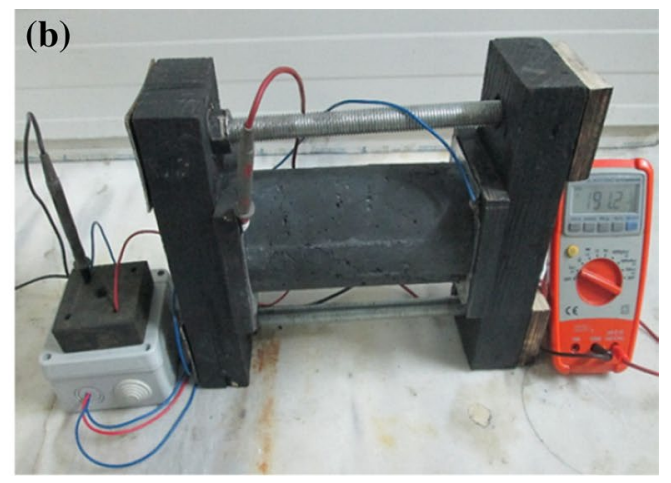

Fig. 2 Two-point resistance measuring equipment: a schematic, b real
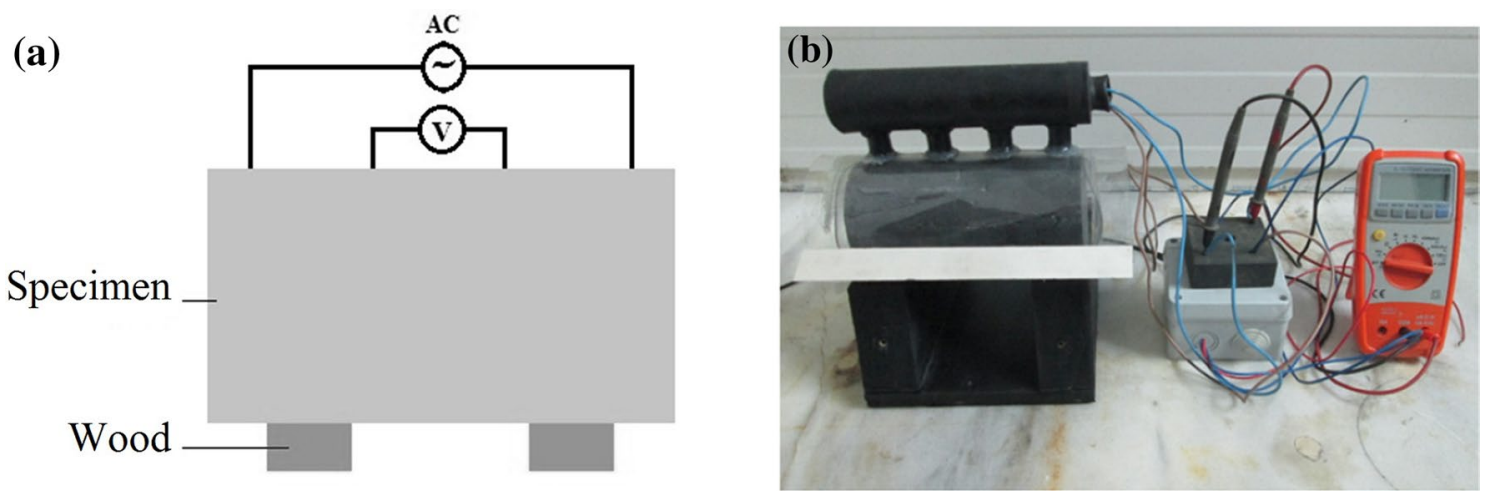

Fig. 3 Four-point resistance measuring equipment: a schematic, b real

Fig. 4 C1760-12 ASTM standard tester and equipment

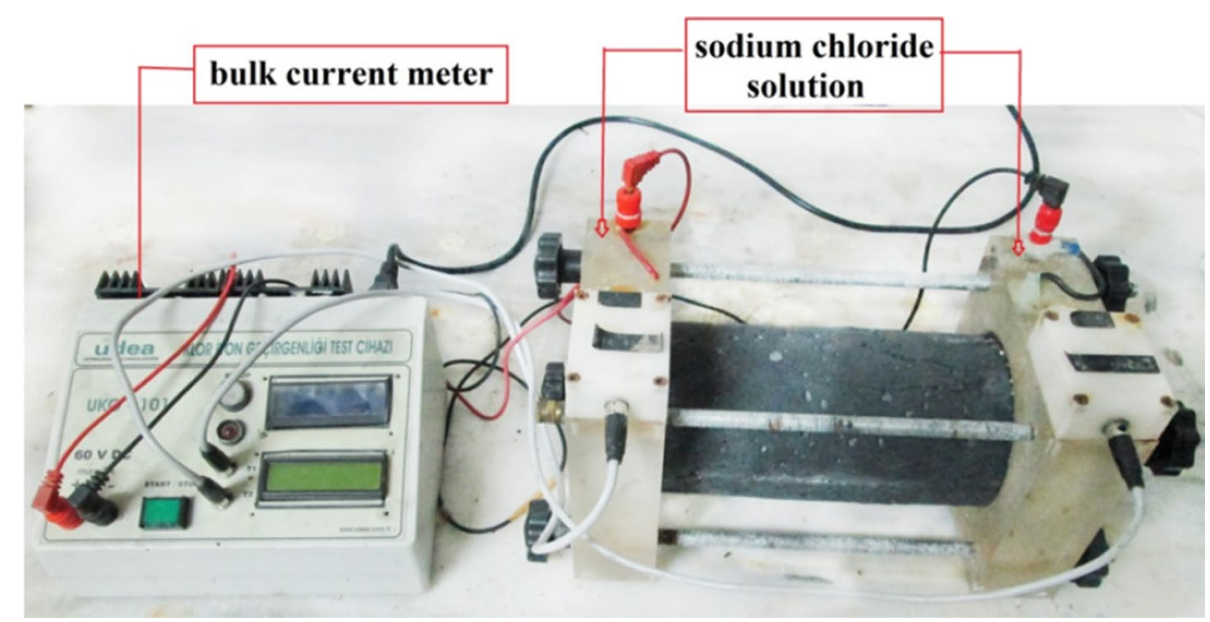

SN Applied Sciences A SPRINGER NATURE journa 
By calculating the inverse of the conductivity, the resistivity of the specimen is obtained (Eq. 6).

$\sigma=K \frac{l}{V} \frac{L}{D^{2}}$

$\rho=\frac{1}{\sigma}$

\section{Result and discussion}

\subsection{Bulk resistivity (BR)}

The electrical resistivity of all mixtures was measured according to the two-point uniaxial method, and the $B R$ values are given in Fig. 5. Also, the bulk resistivity of the control specimen was measured as 22,496 $\Omega \mathrm{cm}$ (Table 4). As shown as Fig. 5, CF has a major role in decreasing the resistivity in conductive concrete. The resistivity value of the specimen containing only 1.0 vol\% CF was decreased by eight times compared to the resistivity value of the specimen containing only 0.5 vol\% CF. When NCB is used together with 0.5 vol\% $C F$, resistivity reduction effect has increased significantly. In the mixture containing 0.5 vol\% CF, the NCB effect increased further when rate increased to over $3 \mathrm{wt} \%$. When the resistivity of the specimen containing only 0.5 vol\% CF was in $1600 \Omega \mathrm{cm}$, the resistivity decreased to $220 \Omega \mathrm{cm}$ when CF is added with $6 \mathrm{wt} \%$ NCB. In the case of maximum (1.0 vol\%) use of $C F$, the effect of $\mathrm{NCB}$ is reduced. In terms of reducing the resistance, the NCB was effective over sevenfold for the mixture containing 0.5 vol\% CF and over twofold for the mixture containing 1.0 vol\% CF. The electrical resistivity values measured by

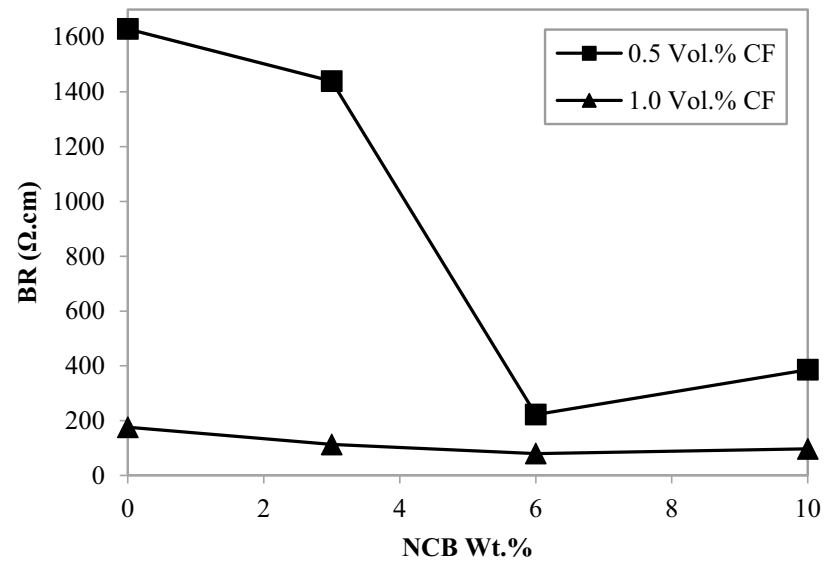

Fig. 5 Bulk resistivity of electrical conductive concretes this method vary between 1600 and $80 \Omega \mathrm{cm}$ depending on the CF and NCB content. Sassani et al. [8] have obtained the lowest resistivity value for conductive concretes containing only $C F$, with this method, as $800 \Omega \mathrm{cm}$.

\subsection{Surface resistivity (SR)}

The SR of the produced conductive concretes was measured between 8800 and $188 \Omega \mathrm{cm}$ (Table 4). Also, this value was measured over 95 thousand for the control specimen. In previous studies, the surface resistivity of normal concrete was measured below 100 thousand [4]. This value is 4.23 times the measured $B R$ value for the control specimen. SR values of conductive concretes are compared in Fig. 6 . The SR values of conductive concretes containing $C F$ resulted in a curve similar to the $B R$ values, depending on the NCB content. However, SR values were measured 2.35-5.40 times the $B R$ values (Table 4). The resistivity of conductive concretes containing 0.5 vol\% CF ranges from 8800 to $560 \Omega \mathrm{cm}$, depending on the NCB content. The lowest resistivity values measured by four-probe methods belong to specimens with 6 wt\% NCB in both 0.5 vol\% and 1 vol\% CF-containing mixtures. The $S R$ value for the mixture containing only 0.5 vol\% CF was measured as $8800 \Omega \mathrm{cm}$, and the value of SR was measured as $560 \Omega \mathrm{cm}$ by adding $6 \mathrm{wt} \%$ $\mathrm{NCB}$ to the same mixture. Also, the SR value for the mixture containing only 1.0 vol\% CF was measured as $569 \Omega \mathrm{cm}$, and the value of $S R$ was measured as $188 \Omega \mathrm{cm}$ by adding $6 \mathrm{wt} \% \mathrm{NCB}$ to the same mixture. Therefore, in terms of reducing the resistance, the NCB had a 15 -fold effect on the mixture containing 0.5 vol\% CF and 3 -fold effect on the mixture containing 1 vol\% CF.

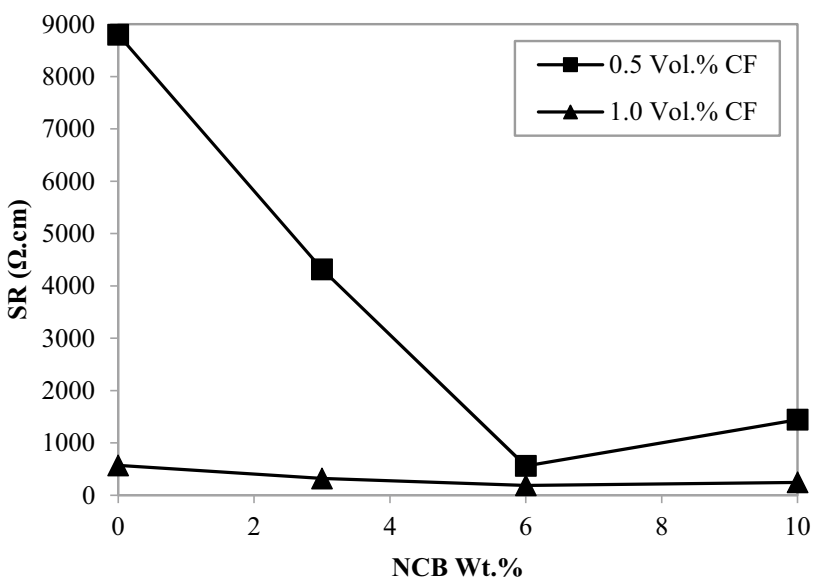

Fig. 6 Surface resistivity of electrical conductive concretes 


\subsection{C1760-12 ASTM resistivity (ASR)}

The ASR values were measured for all conductive concretes and are presented in Fig. 7. In this method, the resistivity values of the concretes containing 0.5 vol\% CF were lower than the $\mathrm{BR}$ values, and the resistivity values of the concretes containing 1.0 vol\% CF were measured higher compared to the $\mathrm{BR}$ values. In concretes containing 0.5 vol\% CF, with an increase in NCB content to $6 \mathrm{wt} \%$, the resistivity value decreased 3.9 times from 3098 to $450 \Omega \mathrm{cm}$. In this mixture group, the resistivity of the specimen containing $10 \mathrm{wt} \% \mathrm{NCB}$ increased to $1087 \Omega \mathrm{cm}$ with a slight rise. According to the measured ASR values in conductive concretes containing $1 \mathrm{vol} \% \mathrm{CF}$, the NCB content did not have a significant effect. This is also true for two-point and four-point methods, as shown in Figs. 5 and 6. Therefore, the effect of the NCB on the resistance decreases as the conductivity increases. However, the resistivity of conductive concretes containing 1 vol\% CF ranges from 679 to 450 under the influence of the NCB. In addition, the resistivity value of the normal concrete measured by this method was determined as 0.32 of $B R$ and 0.08 times of SR (Table 4).

\subsection{Relationship between BR, SR and ASR}

In Fig. 8, the relationships between the resistivity values measured by all three methods are examined linearly. For 0.5 vol\% CF-containing specimens, since the regression coefficient is close to 1 , linear connections between $B R, S R$ and ASR are safe. However, as can be seen from the figure, BR-SR and SR-ASR correlations show some deviation in values. $R^{2}$ coefficient for these relations was obtained as $R^{2}=0.843$ and $R^{2}=0.827$, respectively. The relationship between $B R$ and ASR is stronger than the relationship between the results of other methods; this

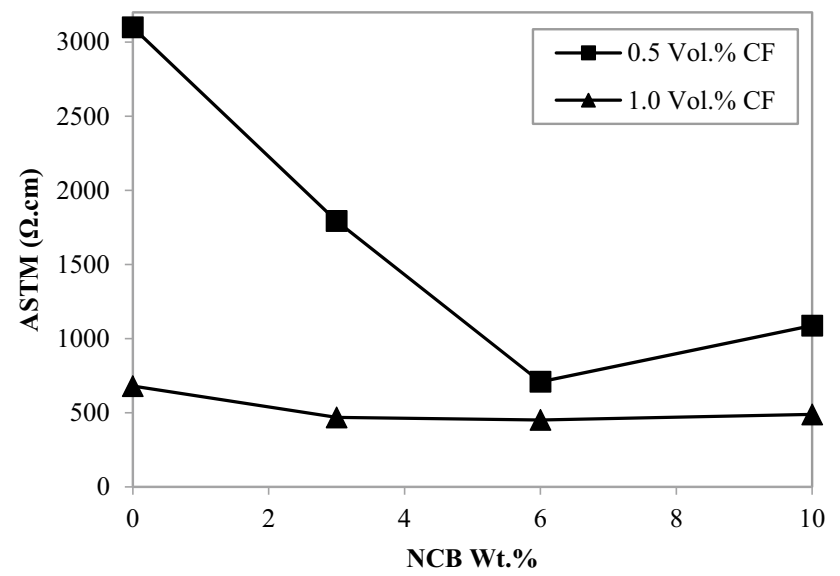

Fig. 7 C1760-12 ASTM resistivity of electrical conductive concretes can also be determined with $R^{2}=0.997$. Generally, when the coefficient $R^{2}$ is above 70 , the corresponding equation is acceptable [28]. For concrete containing $1 \mathrm{vol} \% \mathrm{CF}$, the relationships between the resistivity values measured by all three methods are more faithful. In this mixture group, $R^{2}$ coefficient BR-SR, BR-ASR and SR-ASR relations were obtained above 0.9 . For all mixtures, the relationships between the resistivity values measured by three methods are proposed in Eqs. 7-12. In these equations, Eqs. 7, 8 and 9 belong to BR-SR, BR-ASR and SR-ASR relations, respectively, for concretes having $1000-10,000 \Omega \mathrm{cm}$ resistivity. Equations 10, 11 and 12 belong to BR-SR, BR-ASR and SR-ASR relations, respectively, for concretes below $1000 \Omega \mathrm{cm}$ resistivity.

$$
\begin{array}{ll}
R^{2}=0.8430, & \mathrm{BR}=0.1775 \mathrm{SR}+247.98 \\
R^{2}=0.9971, & \mathrm{BR}=3.5217 \mathrm{ASR}-2107.2 \\
R^{2}=0.8271, & \mathrm{SR}=0.6202 \mathrm{ASR}-117.74 \\
R^{2}=0.9990, & \mathrm{BR}=0.2485 \mathrm{SR}+34.19 \\
R^{2}=0.9194, & \mathrm{BR}=0.3766 \mathrm{ASR}-79.816 \\
R^{2}=0.9194, & \mathrm{SR}=0.3766 \mathrm{ASR}-79.816
\end{array}
$$

\subsection{Compressive test results}

The compressive strength test results of normal concrete and all conductive concrete are summarized in Table 4. The compressive strength of normal concrete was obtained as 44.15 MPa. For the ECCs produced, a single mixture design was used. The compressive strength of conductive concretes is between 42.16 and $53.81 \mathrm{MPa}$. The compressive strength results of the conductive concretes are given in Fig. 9. As shown in the figure, the strength of the concretes containing 1 vol\% CF was higher than the strength of the concretes containing $0.5 \mathrm{vol} \% \mathrm{CF}$, a small amount. Also, the addition of NCB in maximum rate (10 wt\%) to the conductive concrete containing 0.5 vol\% CF reduced the compressive strength. On the contrary, the addition of $10 \mathrm{wt} \% \mathrm{NCB}$ to concrete containing 1 vol\% CF resulted in an increase in compressive strength. During the mixture, it was observed that the addition of NCB in the mixtures containing 1 vol\% $\mathrm{CF}$ increased the paste and gelling properties. In general, the compressive strength of the conducting concrete produced in this study has improved with the additive materials used. 


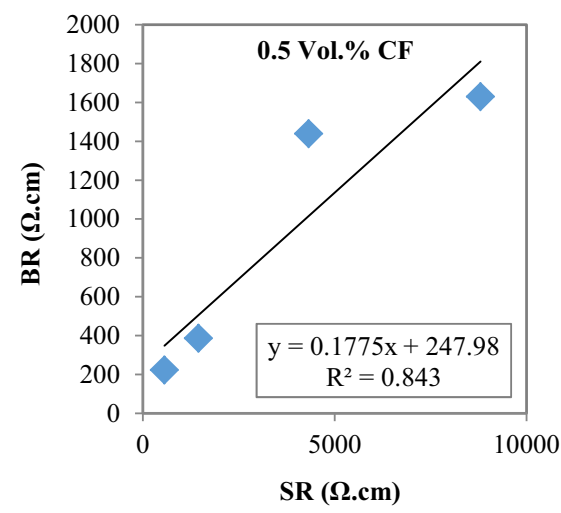

(a)

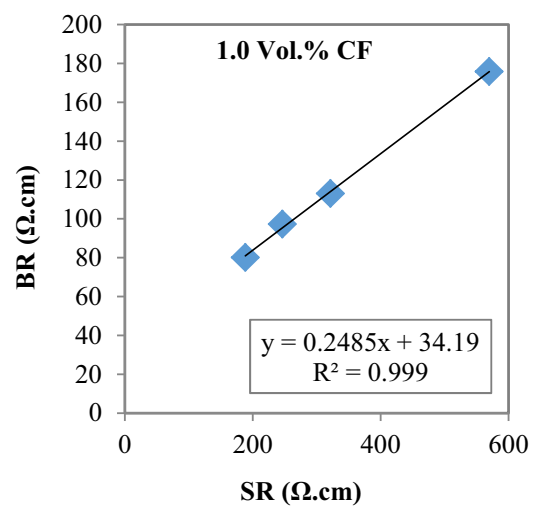

(d)

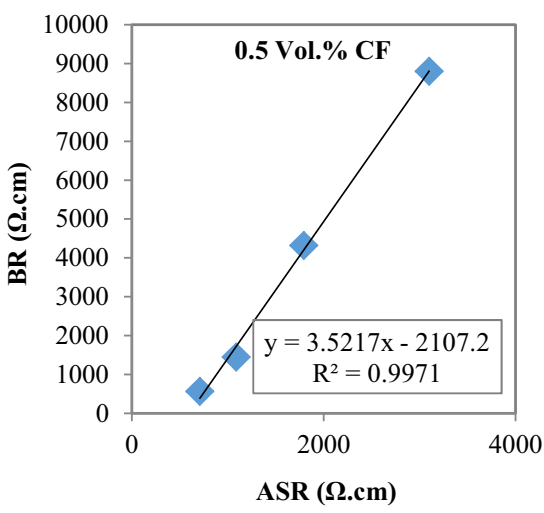

(b)

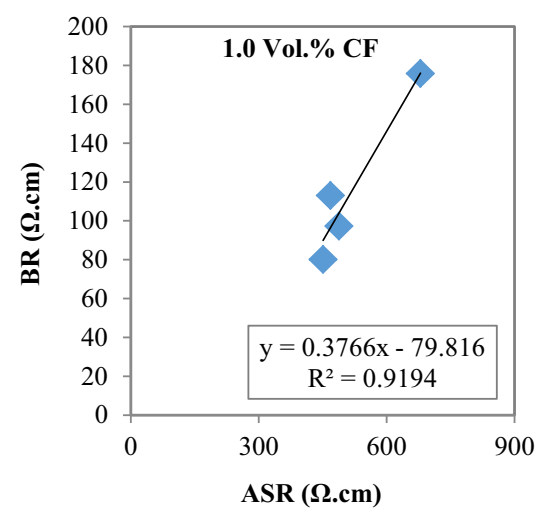

(e)

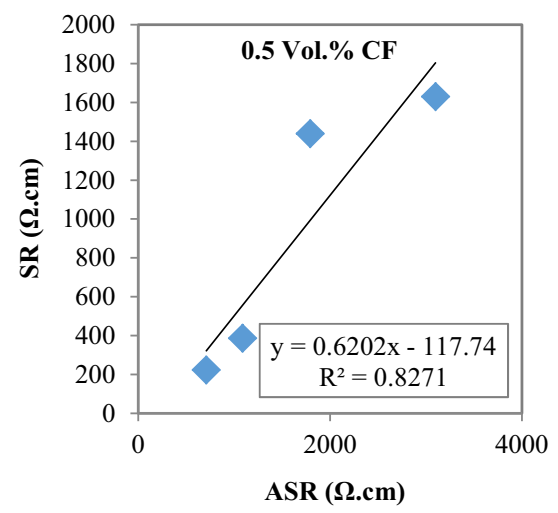

(c)

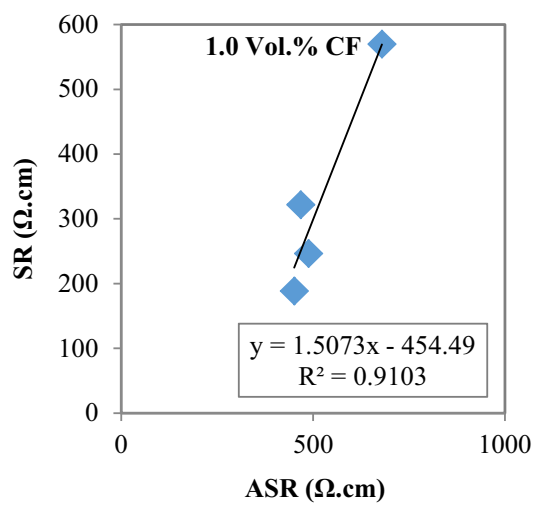

(f)

Fig. 8 Relationship between BR, SR and ASR: a BR-SR: 0.5\% CF, b BR-ASR: 0.5\%, c SR-ASR: 0.5\%, d BR-SR: 1\% CF, e BR-ASR: 1\%, f SR-ASR: 1\%

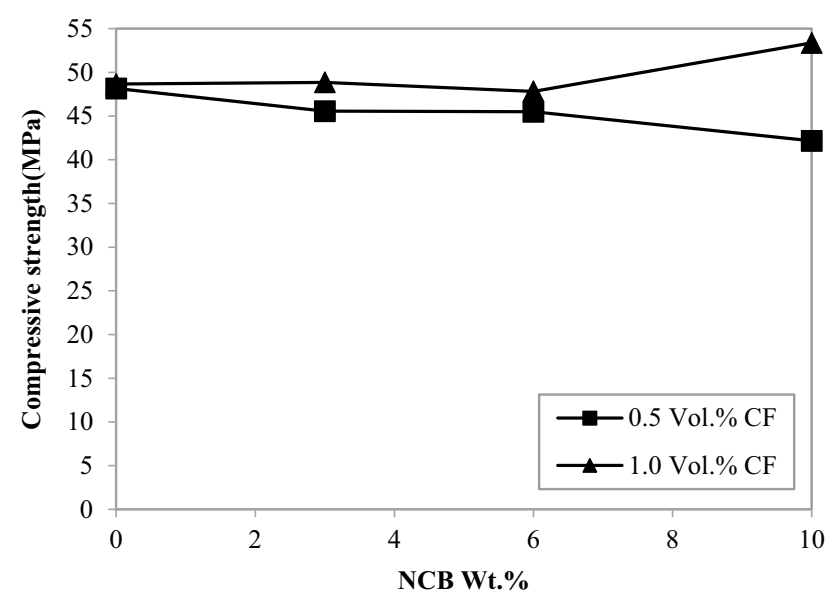

Fig. 9 Compressive strength of electrical conductive concretes

\subsection{Relationship between resistivity and compressive strength}

The relations between the compressive strength results and resistivity values of conductive concretes containing 0.5 vol\% and 1 vol\% CF were investigated. Contrary to the relations between the resistivity values, there was no significant relationship between the compressive strength and the resistivity values.

\section{Conclusions}

- In this study, the resistivity values of the two-phase ECCs produced were measured by three different methods. According to the results measured by all three methods, the resistivity values of all ECCs decreased significantly compared to the control concrete specimen.

- According to the results of compressive strength, CF and NCB additives used in this study had no side effects in the strength of conductive concretes. Also, the maximum compressive strength was achieved by increasing the NCB ratio to $10 \mathrm{wt} \%$ in conductive concretes containing 1 vol\% CF. As observed during the mixture, the increase in the $\mathrm{NCB}$ content has a positive role in the development of workability.

- The resistivity of the conductive concretes containing 0.5 vol\% CF was reduced by increasing the NCB 
content by up to $6 \mathrm{wt} \%$, and an increase in the resistivity was observed when $10 \mathrm{wt} \% \mathrm{NCB}$ was added. The resistance reduction effect of NCB is more pronounced in conductive concretes containing $0.5 \mathrm{vol} \%$ CF. According to the results of all three resistances, the effect of the NCB was greater when $6 \mathrm{wt} \%$ was used.

- Among the three methods, the two-point uniaxial method is the most common resistance measurement method in the literature. The resistivity values obtained with this method were compared with the results in the literature, and their suitability was determined.

- According to the relationships of BR-SR, BR-ASR and SR-ASR, in the conductive concretes containing 0.5 vol\% $C F$, the regression coefficient was over 0.8 , and in the conductive concretes containing 1 vol\% $\mathrm{CF}$, the regression coefficients were exceeded 0.9 . This means that the relations between the three resistivity values are strong.

In this study, the conductivity of $\mathrm{CF}$, the recycled NCB expensive material obtained by pyrolysis method, has increased significantly. For future studies, it is recommended to investigate this waste material together with different materials in conductive concretes. This ensures that the environment is protected from waste tires and carbon black in large volumes. Since there is a good connection between the resistivity values measured by three different methods, the resistivity of the concrete can be measured by the method which can be measured in laboratory environments and the equations obtained in this study can be used to convert the resistivity.

Acknowledgements The authors wish to thank Sakarya University for technical assistance and also thank the director of Sakarya INCI BETON for their support.

\section{Compliance with ethical standards}

Conflict of interest The authors declare that they have no competing interests

\section{References}

1. Parsian H, Tadayon M, Mostofinejad D, Avatefi F (2018) Experimental study on correlation between resistivity measurement methods in concrete. ACI Mater J 115(1):33-45

2. Polder RB (2001) Test methods for on site measurement of resistivity of concrete-a RILEM TC-154 technical recommendation. Constr Build Mater 15(2-3):125-131

3. Tian X, Hu H (2012) Test and study on electrical property of conductive concrete. Procedia Earth Planet Sci 5:83-87

4. Ghosh P, Tran Q (2015) Influence of parameters on surface resistivity of concrete. Cem Concr Compos 62:134-145
5. Chen C-T, Chang J-J, Yeih W-C (2014) The effects of specimen parameters on the resistivity of concrete. Constr Build Mater 71:35-43

6. Wu T, Huang R, Chi M, Weng T (2013) A study on electrical and thermal properties of conductive concrete. Comput Concr 12(3):337-349

7. Downey A, D'Alessandro A, Laflamme S, Ubertini F (2017) Smart bricks for strain sensing and crack detection in masonry structures. Smart Mater Struct 27(1):015009

8. Sassani A, Ceylan H, Kim S, Gopalakrishnan K, Arabzadeh A, Taylor PC (2017) Influence of mix design variables on engineering properties of carbon fiber-modified electrically conductive concrete. Constr Build Mater 152:168-181

9. Wen S, Chung D (2004) Electromagnetic interference shielding reaching $70 \mathrm{~dB}$ in steel fiber cement. Cem Concr Res 34(2):329-332

10. De Volder MF, Tawfick SH, Baughman RH, Hart AJ (2013) Carbon nanotubes: present and future commercial applications. Science 339(6119):535-539

11. Sassani A, Ceylan H, Kim S, Arabzadeh A, Taylor PC, Gopalakrishnan K (2018) Development of carbon fiber-modified electrically conductive concrete for implementation in Des Moines International Airport. Case Stud Constr Mater $8: 277-291$

12. Tuan CY (2008) Implementation of conductive concrete for deicing (Roca Bridge). Nebraska Department of Transportation Research Reports. 25. Project No. SPR-P1(04) P565

13. Yehia S, Tuan CY (1999) Conductive concrete overlay for bridge deck deicing. Mater J 96(3):382-390

14. Galao O, Bañón L, Baeza FJ, Carmona J, Garcés P (2016) Highly conductive carbon fiber reinforced concrete for icing prevention and curing. Materials 9(4):281

15. Ghosh P, Tran Q (2015) Correlation between bulk and surface resistivity of concrete. Int J Concr Struct Mater 9(1):119-132

16. Noushini A, Castel A (2016) The effect of heat-curing on transport properties of low-calcium fly ash-based geopolymer concrete. Constr Build Mater 112:464-477

17. El-Dieb AS, El-Ghareeb MA, Abdel-Rahman MA, El Sayed AN (2018) Multifunctional electrically conductive concrete using different fillers. J Build Eng 15:61-69

18. Lim S, Lee W, Choo H, Lee C (2017) Utilization of high carbon fly ash and copper slag in electrically conductive controlled low strength material. Constr Build Mater 157:42-50

19. Minagawa H, Miyamoto S, Hisada M (2017) Relationship of apparent electrical resistivity measured by four-probe method with water content distribution in concrete. J Adv Concr Technol 15(6):278-289

20. Hou Z, Li Z, Wang J (2007) Electrical conductivity of the carbon fiber conductive concrete. J Wuhan Univ Technol Mater Sci Ed 22(2):346-349

21. Wu J, Liu J, Yang F (2015) Three-phase composite conductive concrete for pavement deicing. Constr Build Mater 75:129-135

22. Whittington $\mathrm{H}, \mathrm{McC}$ arter J, Forde $\mathrm{M}$ (1981) The conduction of electricity through concrete. Mag Concr Res 33(114):48-60

23. Lataste J, Behloul M, Breysse D (2008) Characterisation of fibres distribution in a steel fibre reinforced concrete with electrical resistivity measurements. NDT E Int 41(8):638-647

24. Tuutti K (1982) Corrosion of steel in concrete. Cement-och betonginst, Stockholm

25. Dehghanpour H, Yilmaz K, Ipek M (2019) Evaluation of recycled nano carbon black and waste erosion wires in electrically conductive concretes. Constr Build Mater 221:109-121

26. Rathod R, Goel M, Chakraborty T, Matsagar V, Guégan P, Binetruy $C$ (2019) Experimental and numerical investigations on dynamic behavior of CFRP laminates. SN Appl Sci 1(7):736 
27. Mieda G, Nakamura H, Matsui T, Ochi Y, Matsumoto $Y$ (2019) Mechanical behavior of CFRP on steel surface molded and bonded by vacuum-assisted resin transfer molding technology. SN Appl Sci 1(6):601

28. Dehghanpour H, Yilmaz K (2018) Mechanical and impact behavior on recycled steel fiber reinforced cementitious mortars. Russ J Build Constr Archit 3:67-84

29. Dehghanpour H, Yılmaz K (2018) Microstructure characterization of nano carbon black obtained by combustion method for use in concrete. In: 1st international symposium on light alloys and composite materials (ISLAC'18), UHAKS, Karabuk, Turkey, pp 511-512

30. ASTM D06 (1765) Standard classification system for carbon blacks used in rubber products

31. Lavagna L, Musso S, Ferro G, Pavese M (2018) Cement-based composites containing functionalized carbon fibers. Cem Concr Compos 88:165-171
32. Garzon A, Sanchez J, Andrade C, Rebolledo N, Menéndez E, Fullea J (2014) Modification of four point method to measure the concrete electrical resistivity in presence of reinforcing bars. Cem Concr Compos 53:249-257

33. Astm C (2012) Standard test method for bulk electrical conductivity of hardened concrete. ASTM, West Conshohocken

Publisher's Note Springer Nature remains neutral with regard to jurisdictional claims in published maps and institutional affiliations. 